UDK: 616.89(078)

Izvorni naučni rad

Primljeno: 4.4.2019.

Prihvaćeno za štampu: 31.5.2019.

dr.sci. Vildana Aziraj - Smajić, docent

Univerzitet u Bihaću

Islamski pedagoški fakultet

v.aziraj@gmail.com

\title{
PRIMJENA KBT i EMDR U TRETMANU PANIČNOG POREMEĆAJA: PRIKAZ SLUČAJA
}

\section{Sažetak}

Uvod: U prikazu slučaja opisana je primjena tehnika kognitivno-bihevioralne terapije (KBT) i terapije desensitizacije i reprocesiranja uz pomoćpokreta očiju (EMDR, eng. Eye Movement Desensitization and Reprocessing - EMDR), u tretmanu paničnog poremećaja sa agorafobijom.

Cilj: Ovim prikazom se nastoji prezentirati specificna priroda tretmana paničnog poremećaja koji je imao za cilj povećanje funkcionalnosti klijenta na poslovnom, porodičnom i općenito socijalnom planu.

Prikaz slučaja: Klijent dolazi na tretman u dobi od 26 godina. Ima zavř̌enu srednju školu, zaposlen je, oženjen i živi sa suprugom. Dijagnosticiran mu je panični poremećaj sa agorafobijom radi čega je na bolovanju. Usljed straha od ponovljanja paničnih napada izbjegava izlaske van porodičnog doma i bez sigurnosnih osoba što je znaćajno narusilo kvalitet njegovog funkcioniranja u svakodnevnom životu. Tretman se sastojao od nekoliko dijelova. Prvi se odnosio na psihološku podršku i psihoedukaciju o tretmanu i prirodi paničnog poremećaja. Drugi je uključivao tehnike kognitivno - bihevioralne terapije kao što su kognitivna restrukturacija, identifikacija kognitivnih distorzija, identifikacija, evaluacija i modifikacija negativnih automatskih misli, tehnike abdominalnog disanja, vizualizacije, relaksacije, a nakon odrecivanja hijerarhije situacija koje izazivaju strah kod klijenta provedeno je izlaganje panici imaginacijom te uvježbavanje izlaganja panici u realitetu. Mectutim, $u$ toku tretmana se javljaju smetnje koje ukazuju na prisustvo neproradene traume kao okidača za razvoj simptomatike paničnog poremećaja. U cilju kognitivnog $i$ emocionalnog proradivanja ove traume, $u$ trećem dijelu 
tretmana primijenjena je EMDR terapija. S obzirom da EMDR pristup omogućava aktivaciju adaptivnih neurofizioloških mehanizama koji obezbjectuju funkcionalniju obradu informacija preko procesa rekonsolidacije memorije vezane za stresogena iskustva (disfunkcionalno pohranjena memorija), u tretmanu se osim reduciranja anksioznosti $i$ simptomatskog poboljšanja opravdano očekivalo postizanje značajnih uvida te izmjene uvjerenja i ponašanja vezanih za proživljenu traumu.

Zaključak: Nakon tretmana kod klijenta je došlo do značajnog poboljšanja funkcioniranja kako na kognitivnom, tako na emocionalnom $i$ socijalnom planu. Na temelju aktualnog prikaza slučaja zaključuje se da je kombinacija KBT i EMDR efikasna terapija izbora u tretiranju paničnog poremećaja koji je trigeriran proživljenim traumatskim iskustvom.

Ključne riječi: trauma, panični poremećaj, EMDR, KBT

\section{Uvod}

Izraz panika vodi porijeklo iz grčke mitologije prema kojoj je Pan bio zaštitnik prirode, a rodio se s kozjim nogama, rogat $\mathrm{i}$ bradat da je toliko uplašio rođenu majku koja je doživjela nezapamćen strah koji se i danas naziva paničnim strahom (Pichot, 1996). Prema Međunarodnoj klasifikaciji bolesti (MKB-10), panični poremećaj pripada grupi anksioznih poremećaja. Napadi panike se javljaju spontano i nisu uvjetovani realno ugrožavajućom situacijom, a povezani su sa pretjeranom aktivacijom amigdala na neuralne vanjske podražaje (Begić, 2010). Prema bihevioralnim teorijama, nakon prvog naglog i najčešce objektivno uvjetovanog tjelesnog uznemirenja osoba razvija strah koji može potaknuti svaka promjena u tijelu. Osobe koje razviju agorafobiju upravo iz tih razloga koriste izbjegavanje situacije u kojoj se pribojavaju da će ponovno doživjeti panični napad. Tako se negativnim potkrepljenjem dalje održava ovaj poremećaj i sve više teži ka izbjegavanju okolnosti gdje se osjećaju nesigurnim. Prema kognitivnoj perspektivi ključnu ulogu u razvoju paničnih napada imaju katastrofične interpretacije neočekivanih promjena u tijelu. Kako bi smanjili neugodu izbjegavaju sve situacije u kojima su imali takvo iskustvo i razvijaju niz sigurnosnih ponašanja što posljedično narušava kvalitetu njihovog svakodnevnog života (Jokić-Begić, 2010). 
Panični poremećaj se češće pojavljuje kod žena s tipičnim početkom javljanja u 20-tim godinama života, dok većina slučajeva započinje do 30. godine. Rijetko se javlja nakon 35. godine života. Iako postoje brojne biološke i psihološke teorije koje objašnjavaju nastanak paničnog poremećaja, njegova etiologija do danas nije poznata (Mimica, 2010).

Prema brojnim dosadašnjim istraživanjima efikasnost kognitivnobihevioralne terapije u liječenju paničnog poremećaja je neupitna. Također, sve više se govori u prilog djelotvornosti terapije desensitizacije i reprocesiranja uz pomoć pokreta očiju (eng. Eye Movement Desensitization and Reprocessing - EMDR). U vezi s tim, objašnjava se da se panični napad može doživjeti kao životno ugrožavajući, da je sjećanje na njega toliko specifično da ponekad nalikuje na traumatsko sjećanje posttraumatskog stresnog poremećaja (PTSP) te da se panični poremećaj često razvije nakon doživljavanja stresnih iskustava (Horst i sur., 2017). U prilog primjene EMDR-a ide i prikaz slučaja gdje je korišten u liječenju kompleksnog PTSP-a u komorbiditetu s paničnim poremećajem. Kod ove žene koja je bila u terminalnoj fazi karcinoma pokazano je da EMDR bila terapija izbora s obzirom da KBT nije bio prihvatljiv iz više razloga, a jedan od osnovnih je bio značajan manjak energije koji je bio povezan $s$ osnovnom bolesti, a koja je neophodna za aktivno učešće u KBT-u. Također, u ovakvu primarnu bolest je od ključne važnosti i vrijeme $u$ kojem je moguće ostvariti napredak, pri čemu je EMDR u poređenju sa KBT u prednosti (Udo i Gash, 2012). U preglednom radu koji je obuhvatio šest istraživanja o djelotvornosti primjene EMDR-a u tretmanu anksioznih poremećaja (panični poremećaj s agorafobijom, OKP, dentalna fobija) pokazano je prisustvo nekonzistentnosti rezultatata. Rezultati ovih istraživanja ukazuju na to da se putem EMDR-a ublažavaju anksioznost, panični poremećaj i agorafobija, ali ne utječe značajno na učestalost paničnih napada i javljanje tipičnih anksioznih misli. U vezi s tim autori naglašavaju da je EMDR dobra terapija izbora za panični poremećaj onda kad KBT i tretman izlaganja ne daju očekivane rezultate (Vallente-Gomez i sur., 2017).

U ovom prikazu prezentiran je slučaj osobe s paničnim poremećajem uz agorafobiju kod kojeg je primijenjena kombinacija KBT i EMDR 
terapije u cilju reduciranja psihopatološke simptomatike i poboljšanja funkcioniranja u svakodnevnom životu.

\section{Prikaz slučaja}

Klijent H.H. javlja se na psihološki tretman u dobi od 26 godina. Završio je srednju školu, zaposlen. Odrastao je u potpunoj i funkcionalnoj porodici. Živi sa suprugom i ističe zadovoljstvo bračnom zajednicom. Uspostavlja i održava socijalne kontakte. U svakodnevnom životu pokazuje interes za motociklizam.

\section{Procjena problema}

Klijenta upućuje psihijatar pod Dg. Panične atake. Nakon što je prošao kompletnu medicinsku evaluaciju (kardiolog, pulomolog, neurolog, endokrinolog, niz laboratorijskih testova), pri čemu se isključila organska etiologija njegovih smetnji dolazi na psihijatrijski tretman. Međutim, odbija koristiti ordinirane antidepresive i anksiolitike te pokazuje interes i motivaciju za psihološki tretman. Aktualno se žali na učestalu pojavu iznenadnog i neočekivanog lupanja i "preskakanja" srca uz preznojavanje, slabost, mučninu, "pritisak" u grudima, "vrućinu" i "zujanje" u glavi, vrtoglavicu te osjećaj nestvarnosti. Njegov najveći strah je da će dobiti srčani udar. Iznosi i stvarne somatske tegobe od povreda zadobivenih prilikom šest saobraćajnih nesreća koje je kao motorist imao do sada. U vezi s tim, izdvaja dvije teže fizičke ozljede kao što su puknuća dva rebra, lomovi ruku, nogu i nosa. Kao najveći problem sada iznosi ograničenost kretanja s obzirom da više nije u mogućnosti voziti automobil niti motor, jer se plaši pojave paničnog napada u toku vožnje te da bi mogao izgubiti kontrolu nad sobom. Upravo stoga se osjeća disfunkcionalnim, strahuje za budućnost i da više nikada neće biti onakav kakav je bio ranije. U vezi s tim, opisuje da je ranije bio snažna i stabilna osoba koja je uvijek imala kontrolu nad sobom i ničega se nije plašila. Objašnjava da su svi problemi počeli na radnom mjestu na kojem je dobio prvi panični napad. Do dolaska na tretman imao je ukupno 14 paničnih napada i svi su se dogodili izvan porodičnog doma. 


\section{Faktori rizika}

Identificirani su precipitirajući faktori za razvoj spomenutih problema, a to su višegodišnje nezadovoljstvo radnim mjestom usljed prekomjernog rada i nezadovoljenja socijalnih potreba te anksiozna osjetljivost klijenta. Predisponirajući faktori se ogledaju u manjku povjerenja u zdravstveni sistem (i dalje egzistira sumnja da se radi o organskog etiologiji smetnji) i saobraćajna nesreća. Od ukupno šest saobraćajnih nesreća u posljednjoj nesreći koja se dogodila unazad 8 mjeseci klijentov suvozač je zadobio teže tjelesne povrede i od tada niti jednom nije vozio motor. Prve smetnje koje je osjetio su bile na dan te nesreće i po prvi put je osjetio ,lupanje“ srca koje, kako navodi, nije rezultat „moćnog“ adrenalina koji mu pruža zadovoljstvo u vožnji nego je bilo praćeno osjećajem da ne može doći do daha, hladnim znojem i podrhtanjem nogu.

\section{Konceptualizacija slučaja}

Opis problema, situacija, automatskih misli, fiziologije, ponašanja

a) emocije: osjećaj straha

b) fiziologija: lupanje srca, preznojavanje, povišen krvni pritisak, kratkoća daha

c) kognicije: „poludjet ću“, „dobit ću infarkt", „onesvjestit ću se“, „gubim kontrolu nad sobom“, "ne mogu ovo podnijeti"

d) ponašanje: izbjegavanje posla i samostalne vožnje, kretanja bez supruge kao sigurnosne osobe, često mjerenje krvnog pritiska (najmanje 3 puta dnevno), u trenutku panike držanje za čvrstu podlogu ili za sigurnosnu osobu te prilikom izlaska iz kuće nošenje flašice $s$ vodom.

\section{Moderatori}

Klijent je svjestan konteksta u kojem se panični napadi pojavljuju te su identificirani slijedeći faktori koji utječu na njihovo javljanje. Što se tiče situacijskih faktora problem kod klijenta je izraženiji kad se nalazi van sigurnosti porodičnog doma, a simptomi se smanjuju kad je u društvu bliskih osoba. Na bihevioralnom planu evidentno je da kada miruje i nema dnevnih aktivnosti simptomi anksioznosti su izraženiji, a 
kada je u pokretu, sluša muziku i popravlja motore simptomi se smanjuju. Na kognitivnom planu prisutne su disfunkcionalne misli o vlastitoj slabosti i ranjivosti te preokupiranost financijskim brigama i budućem roditeljstvu povećavaju anksioznost. Nadalje, na afektivnom planu kod klijenta se javlja depresivno raspoloženje kao posljedica uvida u aktualna ograničenja uz strah da je nedostatan kao suprug i budući otac, što dodatno povećava intenzitet anksioznosti. Na interpersonalnom planu primjetno je da zadovoljstvo brakom, porodicom i prijateljima pozitivno utječe na njegovo stanje, ali istovremeno njihov hiperprotektivni odnos prema njemu uzrokuje održavanje njegove ideje da se ne može sam suočiti sa problemom i samim tim inhibira mogućnost njegovog oporavka. Na fiziološkom planu je evidentno da kada osjeti ubrzanje pulsa anksioznost se povećava, usljed čega poseže za mjerenjem krvnog pritiska što dodatno pojačava simptome i u nekim situacijama dovodi i do paničnog napada.

\section{Podržavajuće okolnosti}

Okolnosti koje utječu na održavanje klijentovog paničnog poremećaja su:

a) situacione: odlazak na bolovanje od kojeg ima sekundarnu dobrobit i koje je kontraindicirano u ovom slučaju; drži se porodične kuće kao sigurnosne zone u kojem se panika ne događa;

b) bihevioralne: izbjegavanje svih situacija za koje očekuje da bi mu mogle izazvati panične atake (samostalni izlazak van kuće, vožnja automobila, odlazak na posao), zatim učestalo mjerenje krvnog pritiska i druga sigurnosna ponašanja kao što su nošenje mobitela i flašice s vodom;

c) kognitivne: konstantna promišljanja o vlastitoj neadekvatnosti i slabosti te detaljno planiranje sigurnosnog plana za svaki naredni dan koji ga očekuje;

d) afektivne: konstantna strepnja od ponavljanja paničnih ataka;

e) interpersonalne: izrazito zaštitničko ponašanje okoline.

Posredujuća i bazična vjerovanja

a) Posredujuća vjerovanja 
Stav: Nije poželjno biti slab. Slabići se ne mogu kontrolirati. Anksioznost je apsolutno neprihvatljiva.

Pretpostavka: Svijet je opasno mjesto ako si slab. Ako ne držim stvari pod kontrolom dogodit će se nešto loše.

Pravilo: Uvijek moram imati kontrolu nad sobom. Nikada ne bih smio biti slab. Nikada ne bih smio osjetiti anksioznost.

b) Bazična vjerovanja Ja sam slab.

Ja sam bespomoćan.

Pored toga što su rezultati istraživanja utvrdili da je KBT efikasna terapija izbora za panični poremećaj (istraživanja), opravdanost za primjenu njenih tehnika nalazi se $\mathrm{u}$ klijentovom razumijevanju kognitivno-bihevioralnog koncepta i modela panike, njegovoj motiviranosti za psihoterapijski tretman te odsustvu znakova dublje psihopatološke simptomatike $u$ komorbiditetu $u$ okviru njegove aktualne kliničke slike.

Ciljevi koji su postavljeni zajedno s klijentom su bili:

1) povećati toleranciju na prisustvo anksioznosti i potencijalno javljanje paničnih napada

2) ublažiti i prorijediti pojavu paničnih napada

3) moći samostalno izlaziti van kuće

4) moći samostalno voziti automobil

5) razviti vještine suočavanja za sprječavanje recidiva

\section{Psihološka procjena}

Pored kliničkog intervjua primijenjen je slijedeći psihološki instrumentarij: Revidirane progresivne matrice (RPM), Minessota multifazični inventar ličnosti (MMPI), Bekova skala depresivnosti (BDI), Bekova skala anksioznosti (BAI) i Varteg test crteža (WTZ).

Rezultati pokazuju da se radi o osobi prosječnih intelektualnih sposobnosti sa anksiozno-depresivnom simptomatikom klinički značajnog intenziteta (MMPI202: $\mathrm{L}=3, \mathrm{~F}=5, \mathrm{~K}=5$; $\mathrm{Hs}=18, \mathrm{D}=25, \mathrm{Hy}=18, \mathrm{Pd}=20, \mathrm{~Pa}=11, \mathrm{Pt}=35, \mathrm{Sc}=28, \mathrm{Ma}=12, \mathrm{Si}=7, \mathrm{An}=13$, 
$\mathrm{Ag}=17, \mathrm{Ci}=2 ; \mathrm{BDI}=20 ; \mathrm{BAI}=3$. Analiza projektivnih tehnika (WTZ) potvrđuje prisustvo izražene anksioznosti, inhibiranu motivaciju te sklonost korištenju neadekvatnih strategija za suočavanje sa stresom u svakodevnom životu.

\section{Korištene tehnike $i$ tok tretmana}

U svrhu ostvarenja gore navedenih ciljeva provedena je psihoedukacija o racionali kognitivno-bihevioralnog tretmana te o kognitivnobihevioralnom modelu panike. Zbog učestalosti simptoma hiperventilacije uvježbavana je tehnika abdominalnog disanja, a kasnije $\mathrm{i}$ interoceptivno izlaganje. S obzirom da se klijent žalio da konstantno osjeća da mu je tijelo napeto i u "grču" te da ne može nikako da se opusti, na početku tretmana je uvježbavana i tehnika progresivne mišićne relaksacije. Primijenjena je tehnika kognitivne restrukturacije s akcentom na situacije u kojima se doživljavaju panični napadi. Identificirane su kognitivne distorzije od kojih su najdominantnije katastrofično mišljenje i proricanje budućnosti. Rađeno je na identifikaciji, evaluaciji i modifikaciji klijentovih negativnih automatskih misli. U cilju pripreme za izlaganje određena je hijerarhija situacija koje izazivaju strah kod klijenta. Izlaganju je najprije pristupljeno u imaginaciji, a zatim je putem induciranja panike uvježbavano izlaganje u realitetu. KBT tretman je trajao ukupno 9 seansi.

Međutim, u toku tretmana se javljaju smetnje u vidu nesanice, učestalih košmarnih snova i intruzivnih misli o saobraćajnog nesreći koju je klijent doživio kao vozač motora i u kojoj je njegov suvozač zadobio teže fizičke ozljede. Opravdano je pretpostaviti da je upravo ovo traumatsko iskustvo bilo okidač za razvoj simptomatike paničnog poremećaja. U cilju kognitivnog i emocionalnog prorađivanja ove traume, $\mathrm{u}$ trećem dijelu tretmana primjenjen je standardni protokol EMDR terapije koji se odvija u osam faza.

Cilj EMDR tretmana je bio proraditi maladaptivno pohranjena traumatska sjećanja vezana za saobraćajnu nesreću kako bi klijent došao do adaptivnih odgovora te adekvatno integrirajući ovu traumu u svoje cjeloživotno iskustvo unaprijedio svoje funkcioniranje $u$ svakodnevnom životu. 
U tretmanu se krenulo od prvog puta kad je klijent osjetio simptome hiperventilacije, a to se dogodilo neposredno nakon saobraćajne nesreće. Koncentrirao se na sliku kritičnog događaja negativnu kogniciju, emociju i prateće tjelesne senzacije, korištena je bilateralna stimulacija (BSL) pokretima očiju. Poslije svake serije bilateralne stimulacije klijent je davao povratne informacije o asocijacijama $\mathrm{i}$ eventualnim promjenama koje se dešavaju kod njega. Tokom reprocesiranja uznemirenje je bilo praćeno burnim emocionalnim reakcijama i promjenama $u$ tijelu.

I faza: u prvoj fazi saznaje se o historiji traume. U posljednjih pet godina klijent imao pet saobraćajnih nesreća, ali je posljednja karakteristična po tome što je prvi put imao suvozača koji je bio ozlijeđen i prvi put se osjećao odgovornim za njegov život. Neposredno nakon nesreće (iako je peta po redu) prvi put osjeća i sopstvenu ugroženost uz pojavu prvih simptoma hiperventilacije u vidu ubrzanog lupanja srca, osjećaja nedostatka zraka, vrtoglavice te straha da će dobiti infarkt. Od tada ne vozi motor.

II faza: Priprema klijenta za EMDR putem psihoedukacije o navedenoj vrsti tretmana te uvježbavanja tehnika samoregulacije;

III faza: izvršena je procjena potencijalnih meta (eng. targets) za elaboraciju EMDR-a kako bi se stimulirali primarni aspekti traumatskih sjećanja. Mete su bile: saobraćajne nesreće, nepovjerenje prema zdravstvenim radnicima i doživljaj paničnog napada (prvi, zadnji ili najgori)

a) slika koja predstavlja najgori dio doživljaja: slika sebe samog nakon saobraćajne nesreće uz automatsku misao da će doživjeti infarkt

b) negativna kognicija/uvjerenje u sadašnjosti koje klijentica ima o sebi s obzirom na kritični događaj: ,ja sam krhak, slab“ (problem kontrole)

c) pozitivna kognicija: ono što klijent želi vjerovati s obzirom na kritični događaj: ,ja sam jak ${ }^{6}$

d) validnost pozitivne kognicije (VoK): misleći na ovu sliku/događaj koliko tačnim osjeća ove riječi sada na skali od 1 (potpuno netačno) do 7 (potpuno tačno): 1 (jedan).

e) aktualne emocije u odnosu na kritični događaj: strah, bespomoćnost 
f) aktualna subjektivna procjena uznemirenja s obzirom na kritični događaj: na skalu od 0 (nema uznemirenja) do 10 (najveće uznemirenje) intenzitet uznemirenja klijent procjenjuje da je 10.

g) mjesto fizičke senzacije (gdje osjeća uznemirenje u svom tijelu): grudi.

\section{Tok tretmana}

IV faza: desenzibilizacija u svrhu obrade svih asocijativnih kanala traumatskih sjećanja do njihovog konačnog razrješenja

Prilikom prve EMDR seanse klijent je bio vidno emocionalno uzbuđen i sa početne slike se preusmjerava na bilateralnu stimulaciju u vidu provociranih brzih pokreta očiju. Interesantno je da ih je povezuje s osjećajem užitka i zadovoljstva i u toku procesiranja dalje se saznaje da ga asociraju na "punu liniju" koja se postiže brzinom i kojoj on teži prilikom vožnje motora. Vraća se u rano djetinjstvo (period OŠ), kada gleda film o motoristima i osjeća navalu uzbuđenja, procesira vožnju sa "punim" i "isprekidanim" linijama. Činilo se da se radi o svojevrsnom izbjegavanju suočavanja sa strahom od smrti. Ponovo se vraća na gledanje filma i u pozadini čuje galamu roditelja koji se svađaju. Pojačava ton na TV-u i uživa u zvukovima motora. Sadržajno procesira niz neugodnih životnih situacija koje je, kako navodi, "nadvladao u sebi" tom "punom linijom". Stječe uvid da je postao "ovisan" o adrenalinskoj vožnji, jer mu je služila kao bijeg iz frustrirajućih i neugodnih situacija. U slijedećoj seansi uz istu početnu sliku klijent naglašeno procesira promjene u tijelu pri čemu se dešavaju burne emocionalne reakcije što rezultira paničnim napadom. Želio je izaći vani i prekinuti seansu, ali mu je objašnjeno da je to dio procesa uz podsjetnik onog što smo prošli u okviru prvog dijela tretmana (KBT). Uspijeva proći kroz preplavljujuću anksioznost te je nastavljeno s osnaživanjem resursa. U trećoj seansi s istom početnom slikom klijent dolazi do značajnih uvida. Od nepovjerenja prema zdravstvenim radnicima koje je internalizirao od očevih riječi, uputa i radnji od najranijeg djetinjstva s obzirom da čak i kada bi se fizički ozlijedio otac bi mu rekao da "naši doktori ne znaju ništa" i postupao po vlastitom nahođenju. Prisjeća se kada su mu ljekari stavili longetu na ruku nakon prvog pada s motora da je otac to "trpio" dvije sedmice, a onda uzeo makaze i prerezao je. Navodno to nije rezultiralo negativnim 
posljedicama, ali je njegov otac stolar koji nema medicinsko obrazovanje i prisjeća se niza situacija u kojima su liječnici bili od koristi s akcentom na posljednju saobraćajnu nesreću. U toku procesiranja se dolazi i do njegove želje za odgađanjem roditeljstva koje proizilazi iz straha od sopstvene smrti. S obzirom da je tada došlo do blokiranja procesa u kojem je klijent samo ponavljao isto, kognitivna intervencija terapeuta je bila "kada se na trenutak vratiš u situaciju nakon nesreće u kojem osjećaš strah da ćeš dobiti infarkt koja ti misao prolazi kroz glavu". Klijent je odgovorio "ako on umre, umrijet ću i ja". Idući dalje s tim u procesu klijent dalje dolazi do mjesta gdje se njegov suvozač našao nakon odbacivanja s motora nekoliko metara od njega samog. Ne nalazi ga tu i preplavljuje se strahom. Terapeut sugerira da u ulozi posmatrača pogleda cjelokupni događaj sa strane. U tom procesu vidi sebe, s jedne strane, i vidi suvozača koji je živ i zbrinut od strane zdravstvenih radnika, s druge. Klijent spoznaje da je suvozač za čiji život osjeća odgovornost preživio $i$ da nema opasnosti da će on doprinijeti tome da neko izgubi svoj život. Uviđa da je siguran. Procesira strah od odlaska suvozaču u bolnicu tokom njegovog oporavka, kao i snažan osjećaj krivice koji kod njega potiče potrebu za brzom vožnjom, ali je zakočen strahom od smrti. Stječe uvid da osjeća odgovornost prema još nerođenom djetetu (supruga je trudna) i da takva vrsta vožnje za njega može značiti gubitak prilike da bude otac svom djetetu. Procesira životne prioritete, potrebu da promijeni posao koji će očuvati njegovo psihofizičko zdravlje.

V faza: instalacija koja podrazumijeva povezivanje slike kritičnog događaja, emocija i senzacija sa pozitivnom kognicijom/uvjerenjem " Nisam više u opasnosti, preživjeli smo, neću umrijeti".

VIfaza: skeniranje tijela se uradilo u svrhu provjere prisustva zaostalih napetosti u tijelu klijenta pri čemu nisu identificirani indikatori uznemirenja.

\section{VII faza: zatvaranje}

$\mathrm{S}$ obzirom da je na kraju EMDR seanse potrebno da se klijent vrati $\mathrm{u}$ stanje emocionalne ravnoteže seansa se zatvorila tehnikom relaksacije.

VIII faza: reevaluacija, $\mathrm{tj}$. ponovna procjena se radila narednog susreta. U svrhu procjene rezultata i njihovog održavanja od klijenta je traženo da se ponovno vrati na početnu metu. Pri tome nije identificirano 
prisustvo smetnji, nije došlo do porasta uznemirenja te je zaključeno da su se održali terapijski učinci.

Provedeno je ukupno tri EMDR seanse u trajanju od 60 do 90 minuta i jedna seansa u svrhu reevaluacije i završavanja tretmana.

Po završetku tretmana primijenjene su skale procjene gdje je pokazano $\mathrm{BDI}=8$ i BAI=12 što ukazuje na klinički značajno smanjenje simptoma depresivnosti i anksioznosti.

\section{Praćenje (follow up)}

Nakon tri mjeseca od tretmana klijent ističe zadovoljstvo funkcioniranjem kako na porodičnom, tako i na poslovnom te općenito socijalnom planu. Radi poređenja s ranijim rezultatima primijenjene su samo skale procjene na temelju kojih je zaključeno da su se efekti terapije zadržali u vremenu.

\section{DISKUSIJA}

Tokom KBT tretmana primjetno je značajno poboljšanje u svakodnevnom funkcioniranju klijenta. Stekao je uvid u ono što mu se događa i šta ga inhibira u obavljanju ranije rutinskih aktivnosti. Počeo je samostalno izlaziti vani i izlagati se životnim situacijama. Efikasnije se suočavao sa prisustvom tjeskobe u tijelu, naučio samostalno pratiti, modificirati i evaluirati svoje negativne automatske misli i odvajati svoje misli od realnosti. Međutim, zbog upadljive i iznenadne pojave posttraumatskih stresnih simptoma iz klastera ponovnog proživljanja traumatskog iskustva (intruzivne misli o saobraćajnoj nesreći, košmarni snovi koji u većoj mjeri ukazuju na izražen osjećaj vlastite ugroženosti i strah od smrti) u okviru spomenutog tretmana primijenjen je i EMDR usmjeren na konkretnu traumu.

$\mathrm{Na}$ kraju primjene ovog EMDR tretmana sjećanje na traumatski događaj saobraćajne nesreće više nije izazivao nikakve subjektivne smetnje i tjelesne senzacije. Uz ovo sjećanje klijent je sada povezao pozitivna uvjerenja "nisam u opasnosti", "neću umrijeti" što je značajno ublažilo intenzitet anskioznosti. Sjećanje na prvi panični napad također sada doživljava bez subjektivnih smetnji i tjelesnih senzacija. Naučio je da prihvata $\mathrm{i}$ tolerira povremene oscilacije $\mathrm{u}$ razini anksioznosti $\mathrm{u}$ svakodnevnom životu. Time je značajno reduciran broj paničnih 
napada. Ranije 14 paničnih napada u petnaest dana je svedeno na jedan $\mathrm{u}$ mjesec dana $\mathrm{i}$ to $\mathrm{s}$ kojim se uspijeva adekvatno suočiti. Klijent samostalno funkcionira van kuće, vozi automobil, vratio se hobijima $i$ pokrenuo vlastiti posao.

\section{ZAKLJUČAK}

Nakon tretmana kod klijenta je došlo do značajnog poboljšanja cjelokupnog funkcioniranja u svakodnevnom životu. Na temelju aktualnog prikaza slučaja zaključuje se da je kombinacija KBT i EMDR tehnika efikasna terapija izbora u tretiranju paničnog poremećaja koji je trigeriran proživljenim traumatskim iskustvom. Za pouzdanije i generalizibilnije zaključke neophodno je provoditi kontrolirane studije na većem broju slučajeva.

\section{LITERATURA}

1. Horst, F., Den Oudsten, B., Zijlstra, W., de Jongh, A., Lobbestael, J. \& de Vries, J. (2017). Cognitive Bibevioral Therapy vs. Eye Movement Desensitization and Reprocessing for Treating Panic Disorder: A Randomized Controlled Trial. Frontiers in Psychology , 8, 1409.

2. Jokić-Begić, N. (2010). Bihevioralna paradigma anksioznosti. U: Begić, D. (ur.), Suvremeno liječenje anksioznih poremećaja. (str. 1518) Zagreb: Medicinska naklada.

3. Pichot, P. (1996). Panic: attack and disorder. History of the word and concepts. Encephale, 22(5), 3-8.

4. Mimica, N. (2010). Panični poremećaj. U: Begić, D. (ur.), Suvremeno liječenje anksioznih poremećaja. (str. 25-30) Zagreb: Medicinska naklada.

5. Udo, I. \& Gash, A. (2012). Challenges in management of complex panic disorder in a palliative care setting. BMJ Case Reports

6. Vallente- Gomez, A. Moreno-Alcazar, A., Treen, D., Cedron, C., Colom, F., Perez, V. \& Amman, B.L. (2017). EMDR beyond PTSD: A Systematic Literature Review. Frontiers in Psychology, 8, 1668. 


\section{Vildana Aziraj-Smajić, PhD, spec. of Clinical Psychology}

University of Bihac

Islamic Pedagogical Faculty

v.aziraj@gmail.com

Original scientific article

\section{APPLICATION OF CBT AND EMDR IN THE TREATMENT OF PANIC DISEASE: CASE STUDY}

\section{ABSTRACT}

Introduction: The case study describes the use of techniques of cognitivebehavioral therapy (KBT) and therapy of desensitization and reprocessing with the aid of eye movement (Eye Movement Desensitization and Reprocessing $E M D R$ ), in the treatment of panic disorder with agoraphobia.

Objective: This presentation seeks to present the specific nature of panic disorder treatment aimed at enhancing the functionality of a client in the business, family and general social plan.

Case report: The client comes to treatment at the age of 26 years. He has a high school degree, is employed, married and lives with his wife. He was diagnosed with panic disorder with agoraphobia for which he was on sick leave. Due to the fear of repeating panic attacks, he avoided leaving outside the family home and without someone who will keep an eye on him, which significantly impaired the quality of his functioning

in everyday life. The treatment consisted of several parts. The first concerned psychological support and psycho-education on the treatment and the nature of panic disorder. The second involved cognitive-behavioral therapy techniques such as cognitive restructuring, identification of cognitive distortions, identification, evaluation and modification of negative automatic thoughts, techniques abdominal breathing, visualization, relaxation, and after determining the hierarchy of situations that arouse fear in the client, a panic was exaggerated by imagination and exercise of panic in reality. However, during treatment, there are interferences that indicate the presence of untrained trauma as a trigger for the development of symptomatic panic disorder. For the purpose of cognitive

and the emotional elaboration of this trauma, in the third part of the treatment, EMDR therapy was applied. Since EMDR access allows the 
activation of adaptive neurophysiological mechanisms that provide more functional information processing through the memory reconstruction process related to stress-based memory experience, treatment in addition to reducing anxiety and symptomatic improvement was expected to achieve significant insights and change beliefs and behaviors related to survived trauma.

Conclusion: After treatment with the client, there has been a significant improvement in functioning both on cognitive, emotional and social level. Based on the current case report, it is concluded that the combination of CBT and EMDR is an effective therapy of choice in treating panic disorder that is triggered by the traumatic experience experienced.

Keywords: trauma, panic disorder, EMDR, CBT 


\section{الدكتور المحاضر سيدة ولدانة آزيراي - سمايتش \\ تطبيق EMDR CBT في علاج الاضطراب الهلعي: تقريرحالة}

\section{الخلاصية}

المقدمة: تصف دراسة الحالة استخدام تقنيات العلاج المعرفي السلوكي (CBT)

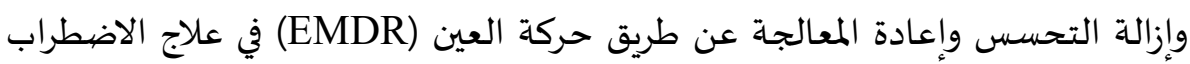
الهلعي مع رُهاب الخلاء (الخوف من الأماكن العامة المفتوحة).

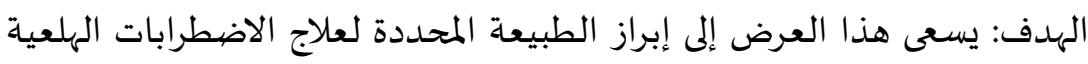

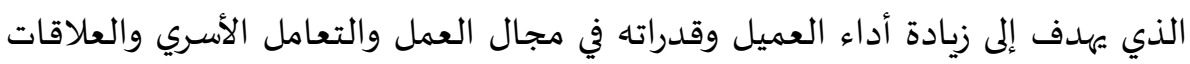
الاجتماعية العامة.

تقرير الحالة: يأتي العميل للعلاج في سن بr عامًا. لدياه شهادة في المدرسة الثانوية،

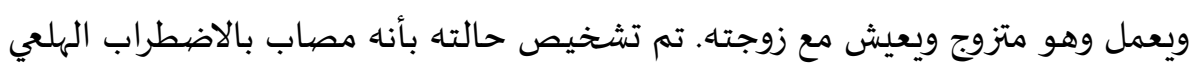

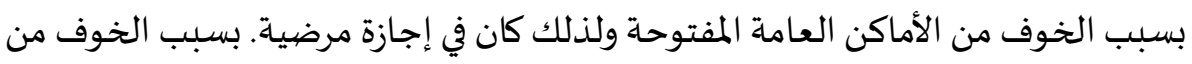

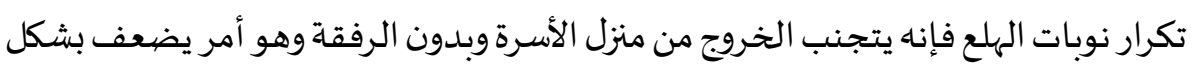
كبير من جودة أنشطته في الحياة اليومية.

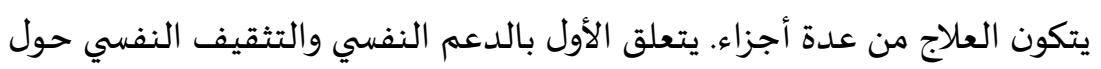
علاج وطبيعة الاضطراب الهلعي. ينطوي الجزء الثاني على تقنيات العلاج المعرفي السلوكي مثل إعادة الهيكلة المعرفياة، وتحديد التشوهات المعرفية، وتحديد الأفكار الأوتوماتيكية السلبية وتقييمها وتعديلها،

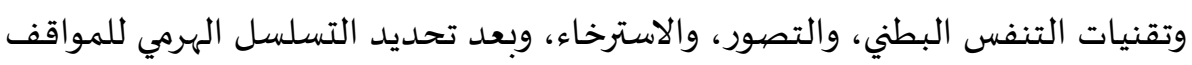

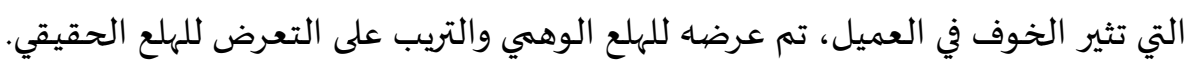

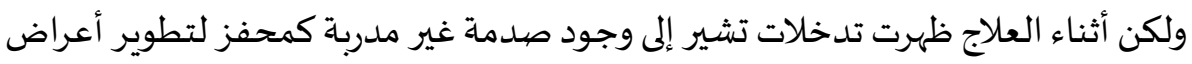

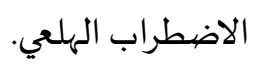

لغرض العلاج المعرفي والعاطفي لهذه الصدمة تم في الجزء الثالث من العلاج تطبيق

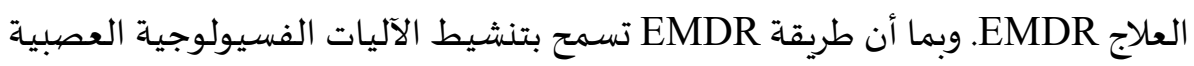
التكيفية التي توفر معالجة أكثر وظيفية للمعلومات من خلال عملية إعادة بناء الذاكرة 
المتعلقة بتجربة الذاكرة المصابة بالضغط النفسي، كان من المتوقع أن يحقق العلاج بالإضافة إلى تقليل القلق وتحسين الأعراض رؤى مهمة وتغيير المعتقدات والسلوكيات المتعلقة بالصيدمة التي عاشها.

الخاتمة: بعد معالجة العميل كان هناك تحسن كبير في الأداء سواء على الخطة

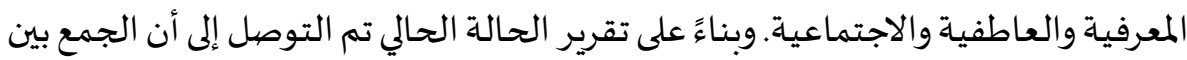

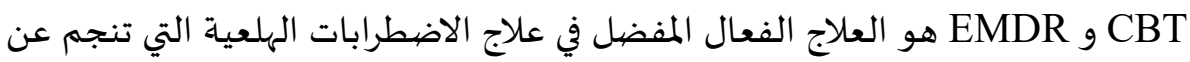

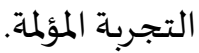

الكلمات المفتاحية: الصيدمة النفسية، الاضطراب الهلعي، EBT EMDR 